\title{
Lighting fires in creative minds Teaching creative writing in special collections
}

$\mathbf{I}_{\mathrm{p}}^{\mathrm{n}}$ his recent book The Program Era, UCLA professor Mark McGurl argues that, "the rise of the creative writing program stands as the most important event in postwar American literary history." ${ }^{1}$ McGurl's claim is controversial, but what is clear is that academic librarians should take notice of the quickly growing creative writing programs on their campuses and develop innovative ways to provide services to them.

The rise of creative writing as an academic discipline has been meteoric. The University of Iowa Writers' Workshop, for instance, began only in 1936. Seminal and influential still, it was the first creative writing degree program in the United States. Other institutions such as Cornell University and the University of Houston fast followed Iowa's lead and became well-known creative writing schools. The Association of Writers and Writing Programs (AWP) currently reports nearly 500 member institutions, and there are many other post-secondary institutions that offer creative writing courses but are not members of AWP. ${ }^{2}$

Growth in the number of students earning creative writing degrees is proportionate to growth in programs. According to statistics provided by the National Center for Education Statistics, U.S. degree-granting institutions awarded 2,333 creative writing degrees in the 1997-98 academic year (1,013 bachelor's degrees; 1,314 master's degrees; and $6 \mathrm{PhD}$ degrees). Within eight years, the total number of creative writing degrees granted annually had nearly doubled to 4,202 in 2005-06 (1,950 bachelor's degrees; 2,236 master's degrees; and $16 \mathrm{PhD}$ degrees). ${ }^{3}$ An article from Cornell
University's Chronicle Online reported in 2007 that, "[m]ore than 500 Cornell undergraduates enroll in campus creative writing courses annually." 4

Creative writing programs offer special collections librarians a unique (and fun) outreach and instruction opportunity. It's commonly assumed that literature derives purely from inspiration-that novels, poems, and essays spring fully formed from their authors' heads - and because of this, creative writing students rarely receive direct outreach from libraries. The assumption, however, misses the importance of research, editing, and publication in the creation of new literature.

Special collections libraries have much to offer creative writing programs. The following are five examples of creative writing sessions I've hosted in the Special Collections Research Center at the University of Chicago (UC) Library. Each suggests a different approach to instruction, but all are unified by the emphasis on collaborative teaching and class discussion. Such examples are always local, of course, and tied to the strengths of unique collections, so I offer them simply as models with the hope that fellow librarians will look at their own collections (physical and electronic) and ask, "What are the possibilities?"

1. Historical fiction. How does a fiction writer create a rounded character if that character lives in the 1920s? What clothes does

David Pavelich is reference and instruction librarian and bibliographer for modern poetry at the University of Chicago Library's Special Collections Research Center, e-mail: pavelich@uchicago.edu

(C) 2010 David Pavelich 
the character wear? What cigarettes does she smoke? What buses or trains does she ride?

"[T]here is generally no substitute for knowing what you are talking about," quipped novelist Wallace Stegner. "Many fictions, whether they involve history or some aspect of contemporary life not in the common experience, or science or small-town politics or the techniques of fighting forest fires, represent more knowledge, both from experience and from research, than shows on the surface." ${ }^{5}$

Writing historical fiction requires research skills, and librarians and archivists are in unique positions to provide this training. Novelist Achy Obejas, teaching in the UC's Graham School of General Studies Writer's Studio, has visited special collections several times with her students to discuss research for fiction writing. The sessions include an introduction to archival research and electronic resources, as well as locating materials like historical atlases, advertisements, and cooking recipes. In a shared conversation, Obejas stresses the importance of food in fictional scenes, while I provide pointers on how to research food from different cultures or time periods.

2. Editorial interventions. In May 2008, poet Garin Cycholl asked his poetry students to read Michael O'Brien's acclaimed Sleeping and Waking, a volume of poetry published by Chicago publisher Flood Editions in 2007. Our collection includes the editorial files for Flood Editions, and Cycholl and his students visited the library to investigate the development of O'Brien's book from manuscript to published book. As a group, we examined O'Brien's original text, read aloud from the editor's recommendations for changes, discovered poems cut from the published version, and discussed whether we agreed or disagreed with the editor's suggestions. Differences of opinion were voiced, and the young poets assumed the role of editor and witnessed the value of the editorial process.

"The students really enjoyed working with the poets' papers," commented Cycholl. "I tried to impress on them an understanding of poetry as a way of being in the world, not simply work carried on alone, but a conversa- tion with other poets, editors, and readers. The poets' letters and exchanges developed students' sense of this conversation. ... These exchanges also influenced the workshop's larger dynamic in that writers began to see the influence of workshop conversations on their own work." ${ }^{\prime \prime}$

3. Drafts. Poet Leila Wilson brought her students from the creative writing program at the School of the Art Institute in Chicago to UC in November 2007. Wilson's class was immersed in the subject of revision, and she wanted her students to see poems by wellknown poets in various drafts, which are found in the records of Poetry: A Magazine of Verse.

Together, we looked at drafts of poems written by poets on the class's syllabus. A sustained discussion centered on two versions of Roethke's poem "Reply to Censure," which appeared in Poetry magazine in November 1937. Accompanying the two versions of the poem is a letter from Roethke to Poetry editor Morton Dauwen Zabel, in which Roethke says, "Thank you for . . . the suggestions, which I have tried to follow. I believe the piece is much stronger, for I have eliminated most of the abstract words." The class discussed how the second version of the poem was possibly less "abstract," adding to students' understanding of both Roethke and the more general concepts of concrete and abstract language.

The manuscripts served as evidence of the labor of craftsmanship. Successive drafts by eminent poets like Roethke make clear that the processes of writing-most specifically revision - apply not just to student writers, but to all poets, including canonical modernists.

4. Versions. Poet Peter O'Leary visited special collections with his beginning poetry writing class in November 2008 to investigate the way Walt Whitman changed the text of Leaves of Grass between 1855 and his death in 1892. Whitman famously revised and added to his long poem, creating a poem by accretion. Students, instructor, and librarian read together from, and discussed, several editions of the poem published during Whit- 
man's lifetime. We also examined examples of Whitman's manuscripts in both facsimile and holograph forms.

"Literature, and the making of literature, is usefully approached from the angle of its material productions," wrote O'Leary to me after the class. "What is it like to publish poetry? Who publishes poetry? And when something is published, does that mean it can't ever be changed? I like bringing young poets to the archives to show them that even the greatest works of literature have undergone changes at the hands of printers, publishers, and even poets themselves, sometimes long after the works themselves have initially appeared."

5. Self-publishing and alternative book forms. In January 2008, poet Jennifer Scappettone wrote to me about assignment for her poetry students. "I want each of the students - 'intermediate' poetry writers-to make a chapbook at quarter's end. So the idea is to expose them to small-press journal editions and chapbooks of differing proportions, materials, and scope- to get their imaginations going, and to reacquaint their generation with (!) the book as medium."

When the class visited special collections, I discussed the history of the pamphlet and chapbook as forms, beginning with German Reformation flugschriften, working through 17th-century English chapbooks, and ending with contemporary avant-garde publications. We also talked about the tradition of selfpublication, from Walt Whitman and Gertrude Stein to the present.

In the end, we examined how such books were made in comparison to the ways students can make quick, handmade books today. Important literary works are often originally published modestly, so we stressed inexpensive printing methods, such as photocopying, and easy hand-binding, like stapling or sewing. Students were empowered to present their own work in an expressive and DIY medium.

\section{Conclusion}

Outreach and instruction for creative writing classes offer a chance to combine traditional special collections instruction methods, such as the "show-and-tell," with the bibliographic instruction techniques of our general reference peers-how to find, how to assess, and how to make use of information-and the workshop approaches found in writing programs. This hybrid technique is a new method for special collections instruction that can be applied to other disciplines.

Providing access to archival and rare books collections for creative writing projects puts our collections to new and exciting uses. For special collections to remain a vibrant and visible presence on university and college campuses, special collections librarians need to reach out to developing user groups. Stegner ends better than I possibly can, with an appeal for openness. "Though it is always helpful to the young to be steered and guided toward what may catch their interest, I would be inclined, also, to throw open the library and let them find many things for themselves. The delight of discovery is a major pleasure of reading; and discovery is one of the best ways to light a fire in a creative mind."

\section{Notes}

1. Mark McGurl, The Program Era: Postwar Fiction and the Rise of Creative Writing (Cambridge, MA: Harvard University Press, 2009).

2. The Association of Writers \& Writing Programs, www.awpwriter.org/membership /index.htm (accessed May 12, 2010).

3. U.S. Department of Education, National Center for Education Statistics. Integrated Postsecondary Education Data System (IPEDS), Fall 2006, (This table was prepared May 2007.), http://nces.ed.gov/programs /digest/d07/tables/dt07_265.asp?referrer=list (accessed May 12, 2010).

4. George Lowery, "Cornell's Creative Writing Program ranked among the nation's best," ChronicleOnline, August 2007, www.news. cornell.edu/stories/Aug07/creativeWriting. gl.html (accessed May 12, 2010).

5. Wallace Stegner, "On the teaching of creative writing," On teaching and writing

(continues on page 313) 
Other specialized resources that did not quite qualify for appearance in Table 2 but for which use is essentially flat throughout the year include the Web of Science, ISI Proceedings, Inspec, NTIS, and most of the FirstSearch resources that are bibliographic but without full-text. High specialization (Early English Books), the provision of data that will be meaningful only to sophisticates (Journal Citation Reports), and purely bibliographic content about library holdings (RLG, OCLC) characterize the few databases for whose use the academic calendar appears to be largely irrelevant.

Experienced methodologists will recognize the risk of committing the ecological fallacy in making inferences about the behavior of individuals based on group differences (in this case, the population of active Virginia Tech users in the summer as opposed to that in the spring). However, political scientists, marketers, and others do routinely draw fairly confident, if hedged, conclusions about individuals from group data, and it would be very difficult to build an argument for the differential patterns we see in the use of these library resources that did not rest on the well-known distinctions in purpose, niche, and intended audience that differentiate many of the online resources that libraries offer. No academic librarian knowledgeable about the offerings of his or her own institution would find it difficult to identify local resources that vary widely along these same dimensions.

\section{So what?}

It's natural to ask whether these data suggest any changes in library practice. One policy implication is that although it makes sense to reduce reference staffing during slow times, there are always people working with our more complex and specialized resources (perhaps even faculty thinking "When the students leave, I can get some real work done on my research?"). Some of our most dedicated users do much of their work when we tend to be lightly staffed, so we should at least make sure that online help is available all the time.

Individual libraries may profit from looking at these ratios in their own cases, and perhaps in making comparisons across institutions. If, for example, a library were to find that a resource it acquired to support general undergraduate instruction is not seeing highly seasonal use, it may indicate that the resource has not been sufficiently promoted to its intended clientele.

The extreme degree of these differences is a useful reminder of just how differentiated our user populations are. We offer a wide range of resources to all, but they are used in highly different ways and to highly different degrees. The data underscore the point that each academic library has user populations, not a user population. And it's not just the parking situation that changes as the year progresses. $\boldsymbol{n}$

\section{("Lighting fires ... ." cont. from page 297)}

fiction, edited by Lynn Stegner (New York: Penguin, 2002).

6. E-mail with Cycholl, July 16, 2009.

7. Theodore Roethke to Morton Dauwen Zabel, Poetry: A Magazine of Verse Records,
Box 40, Folder 15, Special Collections Research Center, University of Chicago Library.

8. E-mail with O'Leary, July 10, 2009.

9. E-mail with Scappettone, January 3, 2008. $n$
("Speculative Realism" cont. from page 308)

- Philosophy Now-Events. The "Events" section of the Web site for the magazine $P b i$ losophy Now has an extensive list of upcoming conferences, workshops, and seminars arranged by geographic location. The list is quite comprehensive in that regularly oc- curring informal coffee shop meetings are included alongside national academic conferences. However, it is not possible to limit the Web site's search function to only the events section, and occasions are not indexed other than by location. Access: http://www. philosophynow.org/events. $\boldsymbol{n}$ 